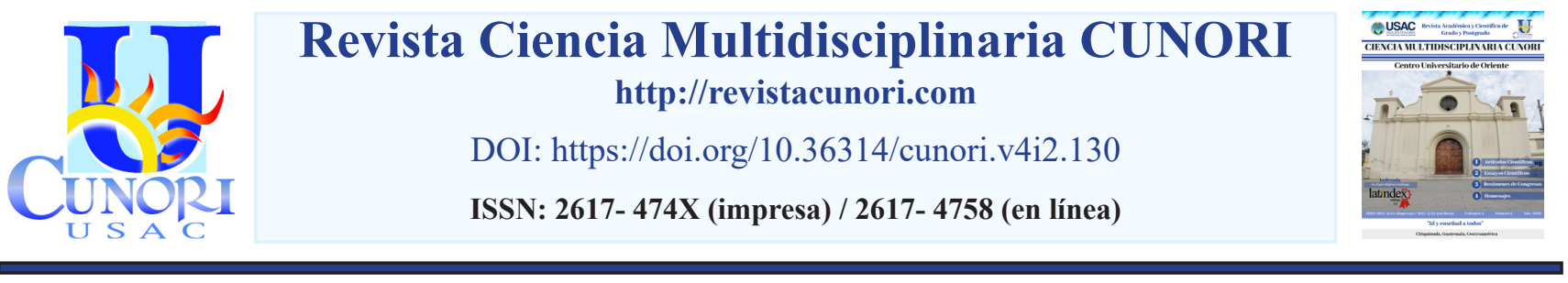

Referencia del artículo

España-Vidal, J. C. (2020). Soberanía y Derecho Internacional -El Caso de Guatemala. Revista Ciencia Multidisciplinaria Cunori, 4(2), 77-81. https://doi.org/10.36314/cunori.v4i2.130

\title{
Soberanía y Derecho Internacional -EI Caso de Guatemala
}

\section{Sovereignty and International Law -The Case of Guatemala}

\author{
Jeraldin Carolina España Vidal \\ Centro Universitario de Oriente, Universidad de San Carlos de Guatemala \\ Recibido: 18 de febrero de 2020 / Revisado: 25 de febrero de 2020 / Aceptado: 25 de mayo de 2020 \\ Disponible en internet el 30 de octubre de 2020
}

*Autor para correspondencia.

Correo electrónico: jeraldinesvidal@outlook.com

Resumen

E 1 enfoque sustancial de este artículo radica en establecer el concepto de soberanía analizado desde la nueva realidad internacional con objeto especifico, señalando elementos para debatir desde otras perspectivas de la comunidad internacional, por medio de un estudio jurisprudencial, jurídico y teórico, sobre el tema: Soberanía y Derecho Internacional -El Caso de Guatemala-. El problema planteado es ¿Se ha transformado el concepto de soberanía como producto de los problemas actuales relacionados con las instituciones creadas por el Derecho Internacional? La hipótesis de trabajo es "La noción de soberanía se ha transformado, como producto de los problema relacionados con las instituciones creadas por el Derecho internacional, en virtud, de que estas instituciones a través de sus resoluciones no han respetado la igualdad y libertad que tiene cada Estado de actuar de conformidad con su ordenamiento interno, atentando contra su poder soberano y evitando que se enmarque en la defensa de la supremacía de su Derecho nacional, provocando con esta injerencia que dichas instituciones internacionales busquen erigirse como una policía mundial". Este estudio se realiza desde la perspectiva del positivismo jurídico, recurriendo a procedimientos que permitan alcanzar los objetivos planteados.

Palabras clave: estado, soberanía, derecho internacional

Abstract

$\mathrm{T}$ he substantial focus of this article lies in establishing the concept of sovereignty analyzed from the new international reality with a specific object, pointing out elements to debate from other perspectives of the international community, through a jurisprudential, legal and theoretical study on the subject: Sovereignty and International Law -The Case of Guatemala-. The problem raised is: Has the concept of sovereignty been transformed as a product of the current problems related to the institutions created by International Law? The working hypothesis is: "The notion of sovereignty has been transformed, as a product of the problems related to the institutions created by international law, by virtue of the fact that these institutions through their resolutions have not respected the equality and freedom that each State has to act in accordance with its internal regulations, undermining its sovereign power and preventing it from taking part in the defense of the supremacy of its national law, causing with this interference that these international institutions seek to establish themselves as a world police force ". This study is carried out from the perspective of legal positivism, resorting to procedures that allow achieving the stated objectives.

Keywords: state, sovereignty, international law 


\section{Introducción}

La presente investigación tiene la finalidad establecer el concepto de soberanía analizado desde la nueva realidad internacional con objeto especifico, señalando elementos para debatir desde otras perspectivas de la comunidad internacional, por medio de un estudio jurisprudencial, jurídico y teórico. El derecho internacional y las ideas de soberanía no son opuestos, sino que se complementan. Un Estado soberano no vive solo, por tanto, es necesario regular ciertas normas para regir la relación conjunta de varios estados soberanos. Si no existiera los Estados soberanos, el derecho internacional sería superfluo (Carpizo, 2019). La soberanía del Estado guatemalteco se ha auto limitado debido a la aceptación y ratificación de acuerdos y tratados internacionales en materia, económica, laboral, penal y de derechos humanos en general.

César Sepúlvedad, distinguido internacionalista afirma que el derecho internacional es una ordenanza jurídica de varios estados soberanos que se obligan mutuamente, y la soberanía del Estado es la aptitud de actualizar y formar el derecho interno y externo, pero este obliga a actuar de conformidad con el derecho (Sepúlveda, 1964). La postura de Flores Olea, dentro de este pensamiento la presencia de los estados soberanos es la existencia del derecho internacional, siendo este la expresión misma de varias voluntades sobernas. En la comunidad internacional, la soberanía del Estado se muestra como la autonomía del mismo, para decidir sobre el ordenamiento jurídico dando la facultad de cambiarlo totalmente sin que otro ente soberano intervenga (Flores Olea, 1969).

El poder interponer problemas de Estado a organismos internacionales, establece límites a la libertad de los mismos de actuar, siendo que al someter en lo cotidiano el termino internacional, la soberanía se autolimita, y es cuando surge el dilema sobre la primacía del derecho interno frente al derecho externo. Incluso con esta reflexión se está reconociendo que los Estados se autoimponen ciertos límites al aceptar y ratificar acuerdos internacionales (Castillo, 2019). El problema planteado es iSe ha transformado el concepto de soberanía como producto de los problemas actuales relacionados con las instituciones creadas por el Derecho Internacional? Aspecto que conlleva al abordaje del denominado tema "Soberanía y Derecho Internacional -El Caso de Guatemala-".

Para esta investigación se planteó como hipótesis "La noción de soberanía se ha transformado, como producto de los problema relacionados con las instituciones creadas por el Derecho internacional, en virtud, de que estas instituciones a través de sus resoluciones no han respetado la igualdad y libertad que tiene cada Estado de actuar de conformidad con su ordenamiento interno, atentando contra su poder soberano y evitando que se enmarque en la defensa de la supremacía de su Derecho nacional, provocando con esta injerencia que dichas instituciones internacionales busquen erigirse como una policía mundial". Las principales fuentes bibliográficas de consulta utilizadas para la realización de la presente investigación, nos llevaron a conocer las opiniones de teóricos expertos en el tema de soberanía y derecho internacional -El Caso de Guatemala-, como Sepúlveda, Flores, Carpizo, Castillo, entre otros. El objetivo del estudio es establecer el concepto de soberanía analizado desde la nueva realidad internacional con objeto especifico, señalando elementos para debatir desde otras perspectivas de la comunidad internacional, por medio de un estudio jurisprudencial, jurídico y teórico. 


\section{Materiales y métodos}

La presente investigación se realizó desde la perspectiva del positivismo jurídico, utilizando procedimientos que permitieron lograr alcanzar el objetivo planteado. Para la recopilación del material teórico necesario para la realización de la investigación, consultando diferentes textos y artículos relacionados con el tema de Soberanía y Derecho Internacional, -El Caso de Guatemala-, escritos por autores nacionales e internacionales, para conocer diferentes posiciones respecto al tema en cuestión; todo lo anterior sobre la base del estudio jurídico, doctrinario y social. Para verificar lo que se entiende por soberanía no se contradiga con lo establecido en la constitución y conocer los límites que la misma establece para actuar de conformidad con la Constitución Política de la República de Guatemala y otras leyes de nuestro ordenamiento jurídico. También conocer la jurisprudencia que asienta la Corte de Constitucionalidad con respecto a la Soberanía.

\section{Resultados}

Es oportuno concretizar los alcances fundamentales que proporcionan primacía al presente artículo. El termino soberanía no es sinónimo de ilegalidad, esta se encuentra restringida por los principios inalienable, imprescriptible, indivisible, los cuales autolimitan la forma en que se aplica. No es comprensible que el concepto de soberanía facilite el quebrantamiento de derechos o a la falta de conocimiento de que los gobernantes de un estado solo son los representantes de la voluntad del pueblo. En este sentido el mismo pensamiento de soberanía contiene sus propios términos para que esta no se ponga en riesgo y para que un Estado tenga siempre el poder de tomar sus decisiones libremente, teniendo un orden jurídico a su servicio, cumpliendo con los fines para los cuales un estado es creado (Carpizo, 2019).

La Noción Absoluta de Soberanía se ha ido debilitando en base a los problemas actuales relacionados con las instituciones creadas por el Derecho Internacional, y esto trae lógicas repercusiones, es por ello que el Estado de Guatemala ha tenido que autolimitarse en sus potestades soberanas para definir su ordenamiento interno. El concepto de soberanía es indiferente por la mayor parte de teóricos del Derecho ordenamiento publico interno a inicios del siglo XX, como algo que no se puede demostrar, y el Estado Soberano se identifica cada vez mas de forma clara con la práctica de varias competencias funcionales. La evolución que ha tenido el concepto de soberanía, ha tenido sus repercusiones lógicas en la comunidad internacional, y en donde el concepto de soberanía tradicional tenía más dificultades en el entorno social (Hinojosa, 2014).

Para el distinguido Doctor Salah, es evidente que hay varios factores de la globalización que han deteriorado el concepto de soberanía tradicional, en este sentido los Estados en la práctica han desaprovechado algunas de las funciones a las que dicho concepto está relacionado. El Doctor Salah da algunos ejemplos de cuatro secciones de intervención estatal que han fichado el declive de la soberanía del Estado ante las exigencias de la globalización siendo los siguientes: los problemas medioambientales, el control de la información, el control de las empresas multinacionales y el control de los flujos monetarios y financieros (Salah, 1996). La democracia del Estado de Guatemala, está apoyada en una serie de situaciones que hacen que el estado restrinja sus cualidades democráticas y soberanas, y que vaya contra lo establecido en nuestra Constitución Política, específicamente en lo relativo a que el Estado de 
Guatemala es independiente, soberano y libre, y que está constituido para avalar el pleno goce de sus libertades y derechos. Libre para poder decidir su política y la forma en que organiza y administra su estado de acuerdo a sus conveniencias y beneficios, sin previa y posterior consulta, sin intervención, supervisión e intrusión de la comunidad extranjera; Independiente, para no depender de la comunidad internacional. Soberano por ejercer un poder supremo dentro de su territorio y sobre sus habitantes.

La Constitución Política de la República de Guatemala, determina en su artículo 122 y 123, que el Estado guatemalteco ejerce completa soberanía en su territorio, el cual está formado por el subsuelo, suelo, el espacio aéreo que se extiende sobre el territorio, aguas interiores y el mar territorial en la extensión que fija la Constitución (Constitución Politica de la República de Guatemala, 1985). Siendo que la presente investigación aportó elementos teóricos en el resultado del análisis se evidencia la situación de que el Estado de Guatemala debe fortalecer la soberanía nacional, y fomentar a la sociedad civil a construir una política correcta, participativa y responsable.

La expresión más pura de nuestro nacionalismo, de la herencia cultural e histórica es la soberanía, y este poder corresponde únicamente a los guatemaltecos. Es el cimiento, en favor de las propuestas para el desarrollo interno y de los intereses que busca Guatemala en la comunidad internacional. Es por ello que es necesario formar un concepto de soberanía que nos ayude a explicarla en la actualidad, y este debe expresar la aceptación de cada fenómeno y problema actual de la soberanía; sin embargo los léxicos de referencia que se enlazan para crear el concepto de soberanía sujetado a la ley en la actualidad de Guatemala, serían: Estado, Poder, libertad y democracia e independencia. Nos referimos a un concepto de soberanía que se sujete a un poder supremo que otorga la constitución al pueblo para elegir a sus autoridades en un proceso libre y democrático, delegando para su ejercicio en sus órganos, siendo independientes para tomar decisiones garantizando así el goce de sus libertades y derechos. Un Estado no vive aislado, sino en un conjunto internacional, es por ello que la Soberanía tiene un aspecto externo, que es la idea de igualdad de todas las naciones: ninguna es más que otra, todas son libres e iguales, por lo tanto, ningún estado tiene derecho a imponer a otro una decisión.

\section{Discusión}

Se probó la hipótesis la noción de soberanía se ha transformado, como producto de los problema relacionados con las instituciones creadas por el Derecho internacional, en virtud, de que estas instituciones a través de sus resoluciones no han respetado la igualdad y libertad que tiene cada Estado de actuar de conformidad con su ordenamiento interno, atentando contra su poder soberano y evitando que se enmarque en la defensa de la supremacía de su Derecho nacional, provocando con esta injerencia que dichas instituciones internacionales busquen erigirse como una policía mundial. La cual quedó comprobada, en virtud que no se respeta a los Estados ni a su soberanía cuando se integra a la Comunidad Internacional. 


\section{Agradecimientos}

Especialmente a las respetables y distinguidas profesionales: Ph.D. Gabriela Patricia Portillo Lemus y Ph.D. María Roselia Lima Garza, quienes ayudaron a la revisión de la investigación.

\section{Referencias}

Carpizo, J. (20 de 07 de 2019). dialnet. Obtenido de https://dialnet.unirioja.es

Castillo, J. (25 de 08 de 2019). scribd. Obtenido de (https://es.scribd.com/document/390697374/ Antologia-Derecho-Constitucional.

Constitución Politica de la República de Guatemala. (1985). Guatemala.

Constitución Politica de la República de Guatemala. (1985). Guatemala.

Flores Olea, V. (1969). Ensayo sobre la Soberanía del Estado. Mexico: Unam.

Hinojosa, L. (2014). Globalización y Soberanía de los Estados. Granada.

Salah, M. (1996). Mondialisation et souveraineté de l'Etat.

Sepúlveda, C. (1964). Derecho Internacional Público (segunda edicion ed.). México: Porrúa.

\section{Sobre la autora}

\section{Jeraldin Carolina España Vidal}

Licenciada en Ciencias Jurídicas y Sociales, Abogada y Notaria egresada del Centro Universitario de Oriente de la Universidad de San Carlos de Guatemala, con Maestría en Derecho Constitucional, ha realizado investigaciones del procedimiento de protección de la mujer embarazada menor de catorce años y la obligación estatal de asistencia.

Copyright (c) Jeraldin Carolina España Vidal

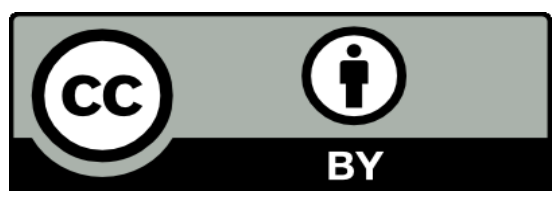

Este texto está protegido por una licencia CreativeCommons 4.0.

Usted es libre para compartir, copiar y redistribuir el material en cualquier medio o formato y adaptar el documento, remezclar, transformar y crear a partir del material para cualquier propósito, incluso comercialmente, siempre que cumpla la condición de atribución: usted debe reconocer el crédito de una obra de manera adecuada, proporcionar un enlace a la licencia, e indicar si se han realizado cambios. Puede hacerlo en cualquier forma razonable, pero no de forma tal que sugiera que tiene el apoyo del licenciante o lo recibe por el uso que hace. 